\title{
M.R. Nejada, F.K. Nadooshana, M.P. Khazaiea, P. Masjedi. An Archaeometrical Analysis of the Column Bases from Hegmatâneh to Ascertain their Source of Provenance
}

\section{Sébastien Gondet}

\section{OpenEdition}

\section{Journals}

Édition électronique

URL : http://journals.openedition.org/abstractairanica/41665

DOI : 10.4000/abstractairanica.41665

ISSN : 1961-960X

Éditeur :

CNRS (UMR 7528 Mondes iraniens et indiens), Éditions de l'IFRI

Référence électronique

Sébastien Gondet, « M.R. Nejada, F.K. Nadooshana, M.P. Khazaiea, P. Masjedi. An Archaeometrical Analysis of the Column Bases from Hegmatâneh to Ascertain their Source of Provenance ", Abstracta Iranica [En ligne], Volume 34-35-36 | 2017, document 75, mis en ligne le 15 juillet 2016, consulté le 28 septembre 2020. URL : http://journals.openedition.org/abstractairanica/41665 ; DOI : https://doi.org/ 10.4000/abstractairanica.41665

Ce document a été généré automatiquement le 28 septembre 2020.

Tous droits réservés 
M.R. Nejada, F.K. Nadooshana, M.P. Khazaiea, P. Masjedi. An Archaeometrical Analysis of the Column Bases from Hegmatâneh to Ascertain their Source of Provenance

\author{
Sébastien Gondet
}

\title{
RÉFÉRENCE
}

M.R. Nejada, F.K. Nadooshana, M.P. Khazaiea, P. Masjedi. « An Archaeometrical Analysis of the Column Bases from Hegmatâneh to Ascertain their Source of Provenance ».

Interdisciplinaria archaeologica, 3, 2, 2012, p. 197-203.

1 Malgré les fouilles archéologiques sur le site, en particulier les fouilles iraniennes des années 2005-2007 dirigées par M. Azarnoush, les bases de colonnes, certaines inscrites, retrouvées sur le tepe d'Ecbatane, dans Hamadān, sont les seuls témoins étudiés de l'occupation achéménide de l'ancienne capitale. Cet article propose une étude basée sur des analyses physico-chimique et pétrographique de la pierre utilisée, couplées à une prospection de carrières situées aux alentours de Hamadān. Il apparaît que ces colonnes ont été fabriquées avec de la pierre venant des affleurements de calcaires situés autour d'Hamadān dans lesquels quelques carrières ont été relevées. Cet article démontre une bonne vitalité des recherches archéométriques en Iran (cf. plusieurs études de ce type publiées dans la région de Persépolis). Il représente également une pièce de plus à verser au dossier, encore peu épais, des études archéologiques sur les carrières antiques en Iran. 


\section{AUTEURS}

\section{SÉBASTIEN GONDET}

CNRS, Paris 